\title{
TEST FIELD FOR AIRBORNE LASER SCANNING IN FINLAND
}

\author{
E. Ahokas *, H. Kaartinen, A. Kukko, P. Litkey \\ Department of Remote Sensing and Photogrammetry, Finnish Geodetic Institute, Geodeetinrinne 2, 02430 Masala, Finland \\ eero.ahokas@fgi.fi
}

Commission I

KEY WORDS: Laser scanning, LIDAR, Calibration, Mobile, Quality, Test field

\begin{abstract}
:
Airborne laser scanning (ALS) is a widely spread operational measurement tool for obtaining 3D coordinates of the ground surface. There is a need for calibrating the ALS system and a test field for ALS was established at the end of 2013. The test field is situated in the city of Lahti, about $100 \mathrm{~km}$ to the north of Helsinki. The size of the area is approximately $3.5 \mathrm{~km} \times 3.2 \mathrm{~km}$. Reference data was collected with a mobile laser scanning (MLS) system assembled on a car roof. Some streets were measured both ways and most of them in one driving direction only. The MLS system of the Finnish Geodetic Institute (FGI) consists of a navigation system (NovAtel SPAN GNSS-IMU) and a laser scanner (FARO Focus3D 120). In addition to the MLS measurements more than 800 reference points were measured using a Trimble R8 VRS-GNSS system. Reference points are along the streets, on parking lots, and white pedestrian crossing line corners which can be used as reference targets. The National Land Survey of Finland has already used this test field this spring for calibrating their Leica ALS-70 scanner. Especially it was easier to determine the encoder scale factor parameter using this test field. Accuracy analysis of the MLS points showed that the point height RMSE is $2.8 \mathrm{~cm}$ and standard deviation is $2.6 \mathrm{~cm}$. Our purpose is to measure both more MLS data and more reference points in the test field area to get a better spatial coverage. Calibration flight heights are planned to be $1000 \mathrm{~m}$ and $2500 \mathrm{~m}$ above ground level. A cross pattern, southwest-northeast and northwestsoutheast, will be flown both in opposite directions.
\end{abstract}

\section{INTRODUCTION}

A permanent test field for airborne photogrammetric systems was established in 1994 (Honkavaara et al., 2008) and a test field for mobile laser scanning (MLS) was initiated in 2009 (Kaartinen et al., 2012) by the Finnish Geodetic Institute (FGI). The experiences obtained by utilizing test fields prove that they are well suited for verifying and comparing the performance of different systems and methods. Test fields can also be utilised in data processing development and testing, e.g. when compiling new algorithms for automatic feature extraction.

Airborne laser scanning (ALS) is a widely spread operational measurement tool for obtaining 3D coordinates of the ground surface. It is important to verify the correct operation of the ALS system before yearly production projects. A permanent test field for ALS provides means for that and FGI is developing such a field using also MLS.

When planning a test field, several aspects have to be considered; e.g. usability, homogeneity versus heterogeneity of the test field features and surroundings. The requirements for the accuracy, as well as the expected geometrical stability of the test field surroundings, set the level of need for the reference data collection methods and spatial coverage. As test field environments and structures are subject to change, and do change, regular updating procedure is required to ensure that the reference data and test data are comparable.

\section{ALS TEST FIELD}

\subsection{Test Field Description}

The requirements set for the new ALS test field were:
- $\quad$ Easily accessible both for reference measurements and ALS operations.

- Versatile scenery: buildings, roads, forest and open areas with a large selection of natural and artificial objects.

- Undulating terrain with flat regions.

The selected test field area is situated in the city of Lahti, about $100 \mathrm{~km}$ to the north of Helsinki. The size of the area is approximately $3.5 \mathrm{~km} \times 3.2 \mathrm{~km}$. Test field location can be reached by car within about an hour from the FGI. Although it is close to some of the largest airfields in Finland, no commercial airways go over it which makes it easier to be used for airborne surveys. As can be seen in Figure 1, the test field has a wide selection of buildings and roof structures: residential areas with detached houses and blocks of flats, industrial buildings etc. Building areas are surrounded by trees and forests, and the ground elevation difference within the test field is about 70 meters.

\subsection{Mobile Laser Scanning Measurements}

Mobile laser scanning can create an accurate point cloud usable in both planimetric and elevation accuracy assessments. In the study by Kaartinen et al. (2012), it was found that $1-2 \mathrm{~cm}$ accuracy (std) in elevation can be reached up to a range of $35 \mathrm{~m}$ with the best MLS systems, and that planimetric accuracy in good GNSS conditions is $2-4 \mathrm{~cm}$.

Reference data was collected with a MLS system assembled on a car (Figure 2). The Roamer R2 system of the Finnish Geodetic Institute (FGI) consists of a navigation system (NovAtel SPAN GNSS-IMU) and a laser scanner (FARO Focus3D 120). Specifications of the navigation system are shown in Table 1, and those of the laser scanner in Table 2. 


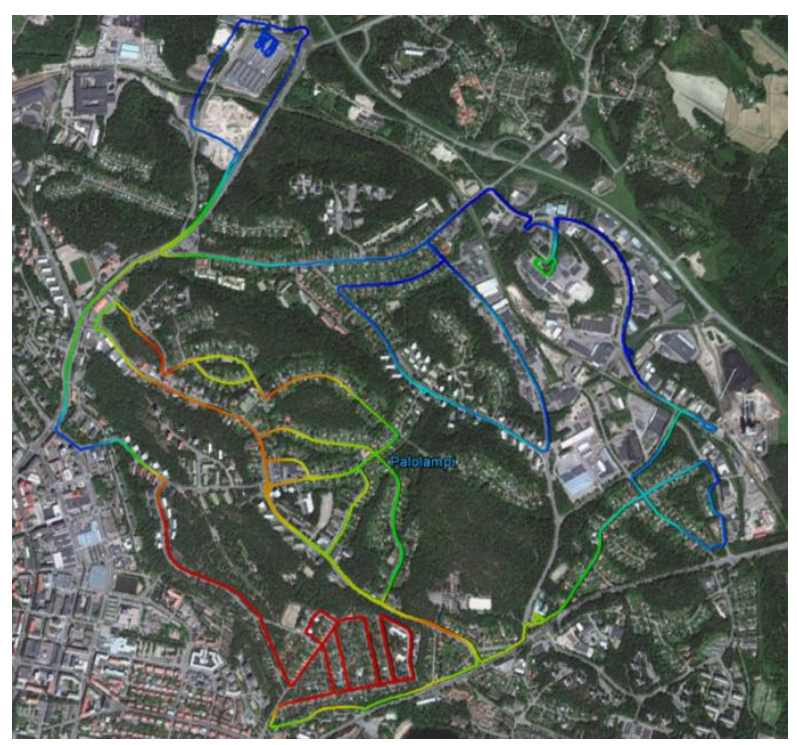

Figure 1. ALS test field area in the city of Lahti. Elevation coloured MLS trajectory shows the current MLS reference data coverage (background image: Google Maps).
The MLS head of the Roamer R2 is a single block of sensors containing laser scanner and multi-constellation GNSS-IMU system for georeferencing the laser point data. The support structure is based on GlobalTruss segments, which allows modularity and versatility for the scanner mount for different platforms (30, 45, and 60 degree angled segments can be used to vary the scan plane orientation).

Data collection for the test field took place in the late afternoon and evening of November $18^{\text {th }}$ 2013. Scanning was performed by capturing 49 lines per second and $244 \mathrm{kHz}$ point measurement frequency. Scanner altitude for the ALS test field data collection was approximately 3.0 meters above ground, and scan plane of the scanner about 15 degree tilted. Some streets were measured in two directions, but most of them in one driving direction only. Example of the collected MLS data can be seen in Figure 3.

\begin{tabular}{|c|c|c|}
\hline Unit & Features & Specifications \\
\hline \multirow{4}{*}{$\begin{array}{l}\text { NovAtel Flexpak6 } \\
\text { GNSS receiver and } \\
\text { GPS-702GG antenna }{ }^{a}\end{array}$} & \multirow[t]{2}{*}{ Frequency } & GPS L1 L2 L2C L5 \\
\hline & & GLONASS L1 L2 \\
\hline & \multirow{2}{*}{$\begin{array}{l}\text { Horizontal position } \\
\text { accuracy (RMS) RTK }\end{array}$} & \\
\hline & & $1 \mathrm{~cm}+1 \mathrm{ppm}$ \\
\hline \multirow{8}{*}{$\begin{array}{l}\text { NovAtel } \\
\text { UIMU-LCI Fiber } \\
\text { optic gyro IMU }\end{array}$} & Output rate & $200 \mathrm{~Hz}$ \\
\hline & Acceleration accuracy (RMS) & $0.004 \mathrm{~m} / \mathrm{s}^{2}$ \\
\hline & Gyro input range & $\pm 800 \mathrm{deg} / \mathrm{s}$ \\
\hline & Gyro rate bias & $<1.0 \mathrm{deg} / \mathrm{h}$ \\
\hline & Gyro rate scale factor & $100 \mathrm{ppm}$ \\
\hline & Angular random walk & $<0.05 \mathrm{deg} / \sqrt{\mathrm{h}}$ \\
\hline & Accelerometer range & $\pm 40 \mathrm{~g}$ \\
\hline & Accelerometer bias & $<1.0 \mathrm{mg}$ \\
\hline
\end{tabular}

Table 1. Specifications of the navigation system (NovAtel SPAN GNSS-IMU).

\begin{tabular}{ll}
\hline Features & Specifications \\
\hline Maximum range & $153 \mathrm{~m}$ \\
Vertical field of view & 305 degrees \\
Ranging error & $\pm 2 \mathrm{~mm} @ 25 \mathrm{~m}$ \\
Wavelength & $905 \mathrm{~nm}$ \\
Beam divergence & $0.19 \mathrm{mrad}, 3 \mathrm{~mm}$ at exit \\
Scan frequency & $3-97 \mathrm{~Hz}$ \\
Point repetition frequency & $122-976 \mathrm{kHz}$ \\
Angular resolution & $0.02 \mathrm{mrad}-5.0 \mathrm{mrad}$ \\
\hline
\end{tabular}

$a \overline{\text { FARO Focus } 3 D \text { Features, Benefits \& Technical Specifications, www.faro.com }}$

Table 2. Specifications of the laser scanner (FARO Focus3D $120^{\mathrm{a}}$ ). 


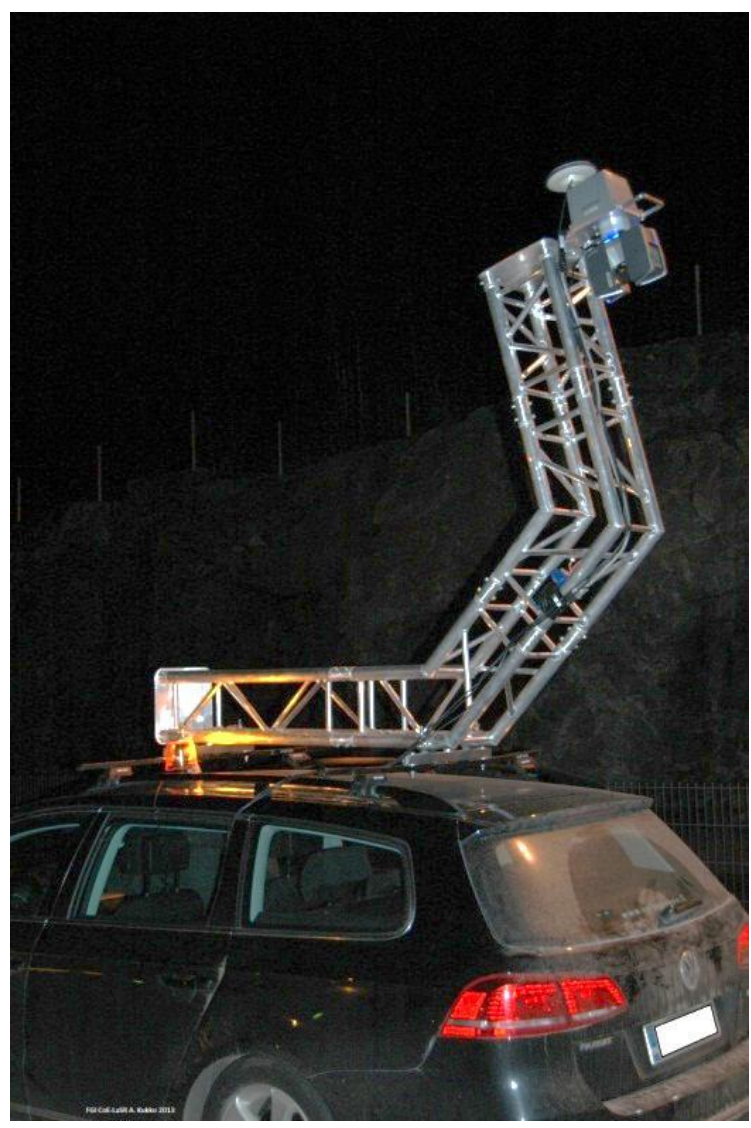

Figure 2. The Roamer R2 MLS of the FGI used for the test field measurements.

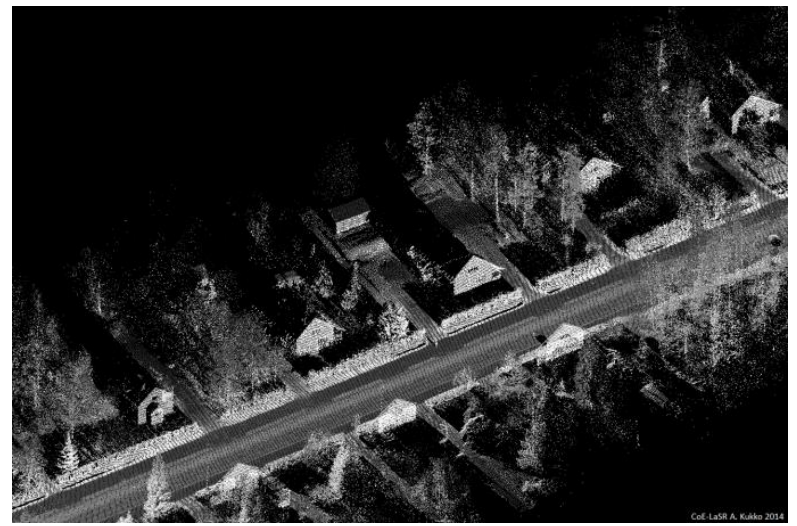

Figure 3. Detail of the street measurements, points coloured by the laser intensity.

\subsection{MLS Point Cloud Processing}

After MLS data collection, the scanner trajectory was computed with Waypoint Inertial Explorer software, using GNSS reference data downloaded from Trimnet GPS/GNSS web service. The acquired point cloud data was georeferenced to ETRS-TM35FIN coordinate system by integrating the measured laser points, trajectory data and synchronization information logged by the navigation unit. As a first step the street points were extracted to be used by the National Land Survey of Finland (NLS) for their ALS calibration. Before the extraction, the georeferenced point cloud was processed using TerraScan software. Isolated points were filtered out and a 'hard surface' algorithm was applied to extract the points on the road surface. These points were then thinned to a point density of an average of 3 points per $\mathrm{m}^{2}$ in order to achieve a better distribution of points on the road, and especially to reduce the amount of points. Original MLS data point density on the road surface was about 350 points per $\mathrm{m}^{2}$. After the processing, the final reference data set delivered to the NLS included about 840 000 road surface points along the MLS driving path.

\subsection{VRS GNSS Measurements}

In addition to the MLS measurements more than 800 reference points were measured using a Trimble R8 VRSGNSS system. Reference points were located along the streets, on parking lots, and white pedestrian crossing line corners which then could be used as reference targets (Figure 4) for data quality analysis. According to Häkli (2004) the RMSE of VRS RTK is $2 \mathrm{~cm}$ in xy and $4 \mathrm{~cm}$ in z. Bilker and Kaartinen (2001) give RMSE accuracies $1 \mathrm{~cm}+1-2 \mathrm{ppm}$ in $\mathrm{xy}$ and $2 \mathrm{~cm}+2 \mathrm{ppm}$ in $\mathrm{z}$ in their RTK GPS report.

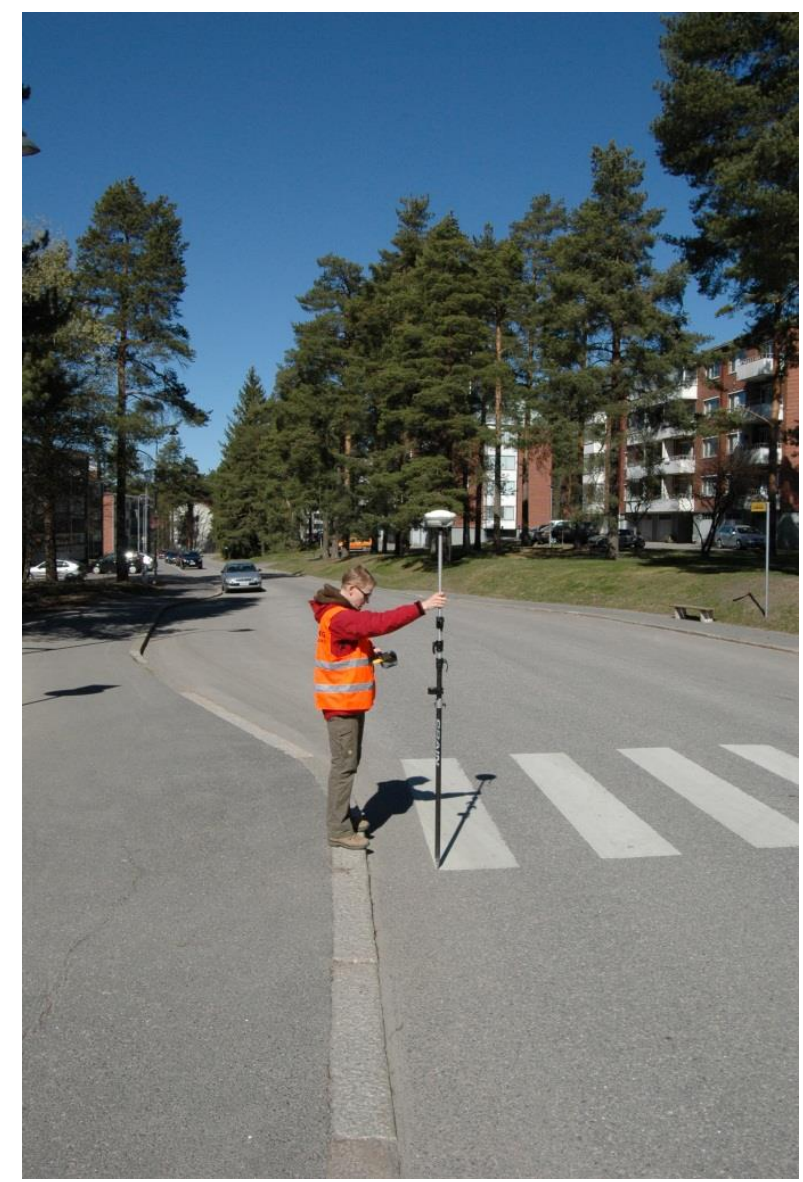

Figure 4. Reference point measurements using a Trimble R8 VRS-GNSS system.

\section{RESULTS}

The street points delivered to NLS were compared against the collected VRS-GNSS reference points. A $1.5 \mathrm{~m}$ search radius from a VRS-GNSS reference point was used for selecting a MLS laser point for comparison. A ground surface slope angle should be less than 20 degrees. Altogether 571 point height differences were calculated and the results are shown in Table 3. 


\begin{tabular}{|l|c|}
\hline & $(\mathrm{m})$ \\
\hline Average dz & -0.012 \\
\hline Minimum dz & -0.131 \\
\hline Maximum dz & 0.065 \\
\hline RMS & 0.028 \\
\hline Standard deviation & 0.026 \\
\hline
\end{tabular}

Table 3. Comparison results of VRS-GNSS check point to the MLS point cloud.

Results show that MLS data and VRS-GNSS points are in accordance with each other and the quality of the measurements are acceptable for ALS system calibration purposes.

\section{CONCLUSIONS}

For scheduled calibration, the flights are planned to be flown at $1000 \mathrm{~m}$ and $2500 \mathrm{~m}$ above ground level. A cross pattern, southwest-northeast and northwest-southeast, will be flown both in opposite directions. The National Land Survey of Finland has already used this test field in spring 2014 for calibrating their Leica ALS-70 scanner for the season 2014. Especially it was found easier to determine the encoder scale factor parameter using the test field with wide spatial area and sufficient data density. In the future more different types of targets are to be extracted from the existing MLS data. More MLS data and reference points in the test field area are to be collected to get a better spatial coverage and completeness for systematic and scheduled calibration operations. This study shows that mobile laser scanning provides an effective and affordable technique for acquisition of test field data for calibrating airborne systems.

\section{ACKNOWLEDGEMENTS}

The authors would like to thank Risto Ilves, Aerial Image Centre of the National Land Survey of Finland, for cooperation in the planning of the test field. Centre of Excellence in Laser Scanning Research (CoE-LaSR, decision number 272195) is gratefully acknowledged for financial support.

\section{REFERENCES}

Bilker, M., Kaartinen, H., 2001. The Quality of Real-Time Kinematic (RTK) GPS Positioning. Reports of the Finnish Geodetic Institute. 2001:1.

Honkavaara, E., Peltoniemi, J., Ahokas, E., Kuittinen, R., Hyyppä, J., Jaakkola, J., Kaartinen, H., Markelin, L., Nurminen, K. and Suomalainen, J., 2008. A permanent test field for digital photogrammetric systems. Photogrammetric Engineering \& Remote Sensing, 74(1), 95-106.

Häkli, P., 2004. Practical test on accuracy and usability of virtual reference station method in Finland. In Conference Proceedings of FIG Working Week 2004 (Athens, Greece: FIG), pp. 1-16.

Kaartinen, H., Hyyppä, J., Kukko, A., Jaakkola, A. 2012. Benchmarking the Performance of Mobile Laser Scanning Systems Using a Permanent Test Field. Sensors 2012, 12(9), 12814-12835; doi:10.3390/s120912814 